\title{
Microwave Sintered Fe/MgO Soft Magnetic Composite
}

\author{
R. Bureš ${ }^{a, *}$, M. FÁberová ${ }^{a}$, P. Kollár ${ }^{b}$, J. FÜZer $^{b}$, S. DobÁK ${ }^{b}$, F. Onderko ${ }^{b}$ \\ AND P. KUREK ${ }^{a}$ \\ ${ }^{a}$ Institute of Materials Research, Slovak Academy of Sciences, Watsonova 47, 04001 Košice, Slovak Republic \\ ${ }^{b}$ Institute of Physics, Faculty of Science, P.J. Šafárik University in Kosice, \\ Park Angelinum 9, 04154 Košice, Slovak Republic
}

\begin{abstract}
Micro/nano soft magnetic composite based on the Fe microparticles and the $\mathrm{MgO}$ nanoparticles was prepared by cold pressing followed by microwave sintering. Magnetic and mechanical properties of the green compact as well as sintered samples were measured. Coercivity, permeability, resistivity, elastic modulus and transverse rupture strength values in dependence on $\mathrm{MgO}$ content were investigated. The influence of $\mathrm{MgO}$ content ratio on properties was different in the case of as pressed green samples in comparison to sintered bodies. Microstructure formation and its influence on mechanical and magnetic properties are discussed. The coercivity of the green compacts with 1-5 wt\% of $\mathrm{MgO}$ exhibits approximately $460 \mathrm{~A} / \mathrm{m}$ and after sintering decreases to approximately $290 \mathrm{~A} / \mathrm{m}$. The real part of complex permeability at the frequency of $100 \mathrm{kHz}$ exhibits a maximum for $2 \mathrm{wt} \%$ of $\mathrm{MgO}$ in green compacts, while for $10 \mathrm{wt} \%$ in sintered samples. It was observed that increase of the content of $\mathrm{MgO}$ causes decrease of the permeability. Properties of the sintered composite are related to formation of magnesium ferrite as well as volume distribution of residual $\mathrm{MgO}$ in dependence on initial $\mathrm{MgO}$ ratio.
\end{abstract}

DOI: 10.12693/APhysPolA.131.780

PACS/topics: 81.05.--t, 75.50.--y, 62.20.--x

\section{Introduction}

Soft magnetic composites (SMC) are produced by the powder metallurgy method from ferromagnetic particles coated with a thin electrically insulating layer. Widely used shaping method is cold pressing, which introduces an elastic and plastic deformation to the composite. Structural discontinuities, imperfections as well as residual stresses induce changes of magnetic and mechanical properties [1]. Inorganic coatings, based on $\mathrm{MgO}, \mathrm{Al}_{2} \mathrm{O}_{3}$ and $\mathrm{SO}_{2}$, with high thermal stability are investigated to allow stress relaxation heat treatment at temperature higher than $600{ }^{\circ} \mathrm{C}[2,3]$. Advanced compaction methods are investigated with focusing on optimization of intrinsic structure of SMC's and other functional materials $[4,5]$. Microwave sintering is progressive heat treatment technique. Microwave heating is fundamentally different from conventional heating in the way how thermal energy is delivered to the material. It has been observed improvement of microstructure, physical and mechanical properties of microwave sintered composites in comparison to conventionally sintered materials [6]. Subject of this work is the microwave sintered micro-nano composite based on $\mathrm{Fe} / \mathrm{MgO}$. Microstructure formation, magnetic and mechanical properties were investigated.

\section{Experimental material and methods}

Technically pure Fe microparticles (ASC 100.29, Höganäs $\mathrm{AB}$, mean size of powder particles $d=100 \mu \mathrm{m}$ )

\footnotetext{
*corresponding author; e-mail: rbures@saske.sk
}

were dry coated by $\mathrm{MgO}$ nanoparticles (MTI Corp., mean size $d=30 \mathrm{~nm}$ ) using the Resonant Acoustic Mixing method in Resodyn LabRAM mixer. $\mathrm{Fe} / \mathrm{MgO}$ powders with $1,2,3,5,10$ and 13.85 wt\% of $\mathrm{MgO}$ content were uniaxially cold pressed at pressure of $600 \mathrm{MPa}$. Sintering was provided in multimode microwave (MW) cavity with controlled power from $100 \mathrm{~W}$ to $3 \mathrm{~kW}$ at constant temperature of $800^{\circ} \mathrm{C}$, for $15 \mathrm{~min}$, in dry air atmosphere. Multimode MW oven Hamilab V3000 (Synotherm Corp.) was equipped by IR pyrometer Optris.

Microstructure and EDS analyses were provided by scanning electron microscope (SEM) JEOL 7000F and inverse light microscope Olympus GX-71 (OM). For the investigation of magnetic properties, the samples were used in the form of a ring with one toroid. Complex permeability (real and imaginary part of complex permeability) were measured with an impedance analyzer (HP $4194 \mathrm{~A})$ at $100 \mathrm{kHz}$. Coercivity $\left(H_{c}\right)$ of green compacts and sintered samples was measured using Koerzimat HCJ 1.097 (Foerster). The Young modulus $(E)$ was measured by impulse excitation technique using Buzz-o-sonic system (BuzzMac). Flexural strength was characterized by measurement of transverse rupture strength (TRS) using three point bending test on universal testing machine Tiratest 2300 .

\section{Results and discussion}

Magnetic and mechanical properties of the green compact as well as sintered samples were measured. Coercivity, permeability, resistivity, elastic modulus and transverse rupture strength values in dependence on $\mathrm{MgO}$ content were investigated. Relative density of the green compact and sintered sample, in Fig. 1, is nearly constant up 
to $3 \mathrm{wt} \%$ of $\mathrm{MgO}$. Relative densities decrease with $\mathrm{MgO}$ addition more than $3 \mathrm{wt} \%$. Slightly lower values of the sintered density in comparison to green density is result of $\mathrm{MgFe}_{2} \mathrm{O}_{4}$ formation in process of the sintering in air atmosphere as it is presented in our previous work [7].

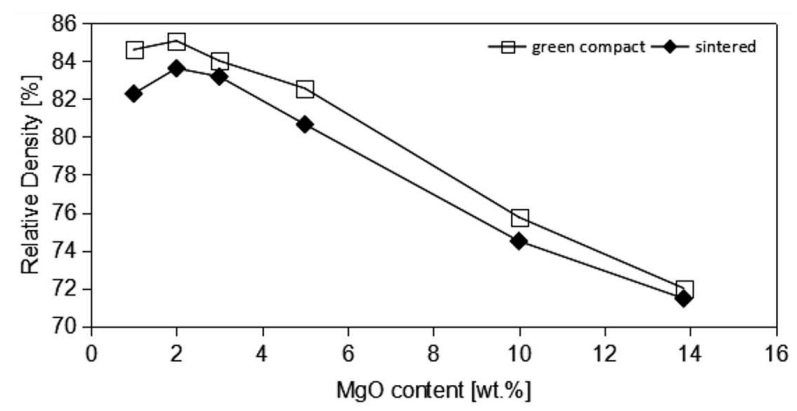

Fig. 1. Relative density versus $\mathrm{MgO}$ content.

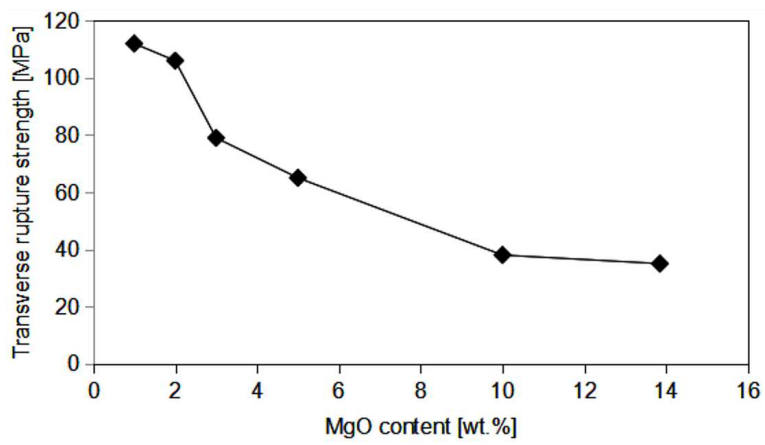

Fig. 2. Flexural strength versus $\mathrm{MgO}$ content.

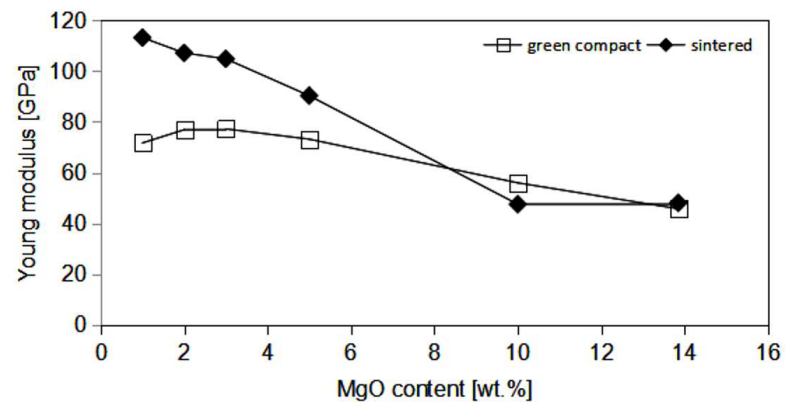

Fig. 4. Coercivity versus $\mathrm{MgO}$ content.

Flexural strength of the sintered composite, in Fig. 2, decreases with increase of $\mathrm{MgO}$ content. Dependence of the Young modulus of the green compact on $\mathrm{MgO}$ content is shown in Fig. 3 and is in agreement with relative green density. The Young modulus of the sintered composite decreases with increase of $\mathrm{MgO}$ content up to $10 \mathrm{wt} \% \mathrm{MgO}$. At this point, elastic properties of sintered composite are lower in comparison to green compact. $\mathrm{MgO}$ content higher than $10 \mathrm{wt} \%$ discontinues decrease of the elastic and mechanical properties.

Coercivity of the green compact, in Fig. 4 is nearly constant. Lower value of coercivity of the sintered composite

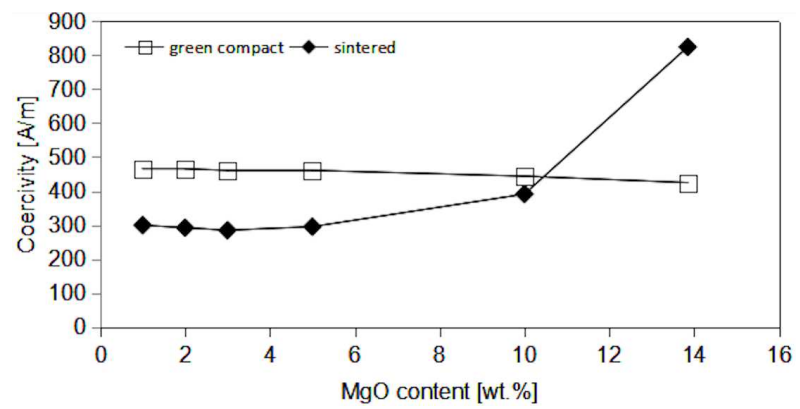

Fig. 4. The Young modulus versus $\mathrm{MgO}$ content.

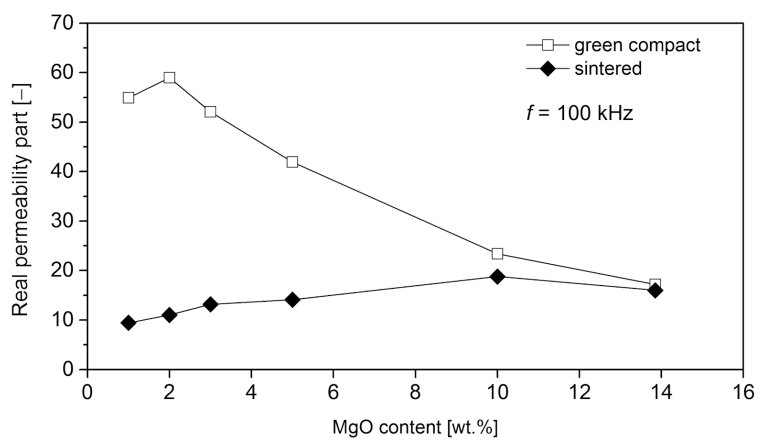

Fig. 5. Real part of complex permeability of $\mathrm{Fe} / \mathrm{MgO}$ composites at $100 \mathrm{kHz}$.

is a result of recovery and stress relief processes induced by sintering. Coercivity of the sintered composite slightly increases with increase of $\mathrm{MgO}$ content higher than 5 wt $\%$. MgO content higher than $10 \mathrm{wt} \%$ causes rapid increase of the coercivity value.

The coercivity of the green compacts within 1-5 wt\% of $\mathrm{MgO}$ exhibits approximately $460 \mathrm{~A} / \mathrm{m}$ and after sintering decreases to approximately $290 \mathrm{~A} / \mathrm{m}$. Figure 5 provides behavior of real relative permeability component versus $\mathrm{MgO}$ content at given magnetizing frequency of $100 \mathrm{kHz}$. In green compacts, this permeability possesses a maximum at $2 \mathrm{wt} \% \mathrm{MgO}$ and then decreases. However in sintered cores, $\mathrm{MgO}$ content causes an increase in permeability up to $10 \mathrm{wt} \%$ of $\mathrm{MgO}$.

Observation of microstructure by light microscopy in Fig. 6 shows that $\mathrm{MgO}$ ratio up to $5 \mathrm{wt} \%$ leads to distribution of the $\mathrm{MgO}$ nanoparticles to the voids within irregular shaped iron microparticles. $\mathrm{MgO}$ ratio about $1 \mathrm{wt} \%$ is not enough to continuous insulation of iron particles. $\mathrm{MgO}$ content from 2 to $5 \mathrm{wt} \%$ provide suitable insulation network in the composite. There is not significant increase of the porosity with increase of $\mathrm{MgO}$ ratio. Decrease of the green density with increase of $\mathrm{MgO}$ content is result of $\mathrm{MgO}$ distribution changes in process of cold pressing. On the other hand, decrease of sintered density is caused by formation of $\mathrm{MgFe}_{2} \mathrm{O}_{4}$ interlayer among iron and $\mathrm{MgO}$ particles. $\mathrm{MgO}$ ratio up to $3 \mathrm{wt} \%$ leads to formation magnesium ferrite without residual content of $\mathrm{MgO}$ in microstructure of sintered composite as it is shown in Fig. 7 (top). Higher $\mathrm{MgO}$ ratio leads to microstructure with residual $\mathrm{MgO}$, which cases the de- 
gradation of mechanical and magnetic properties. These observations are related to result of study of the effect of iron island morphology and interface oxidation on the magnetic properties of $\mathrm{Fe}-\mathrm{MgO}$ thin film composites published by Spurgeon et al. [8].

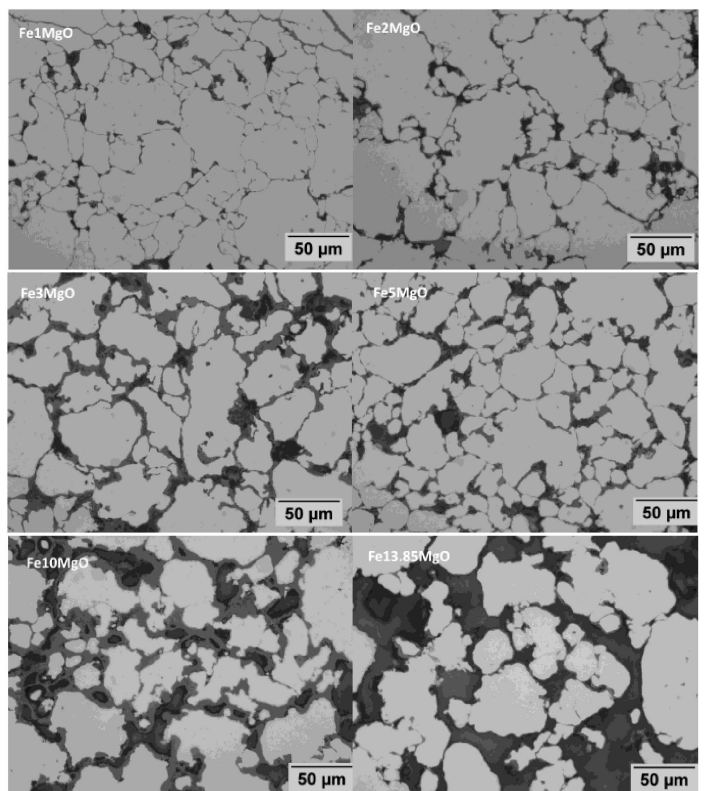

Fig. 6. Microstructure of sintered $\mathrm{Fe} / \mathrm{MgO}$ composite, OM.
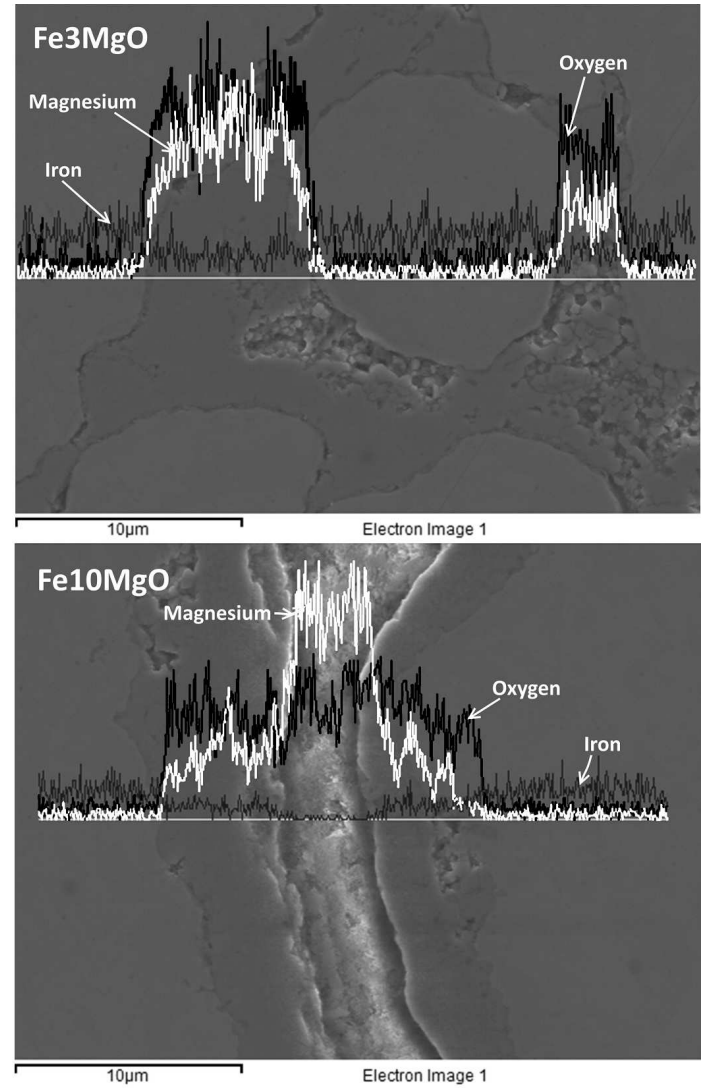

Fig. 7. SEM microstructure and EDS line analysis of sintered $\mathrm{Fe} / \mathrm{MgO}$ composite.

\section{Conclusions}

Micro/nano soft magnetic composite based on the $\mathrm{Fe}$ microparticles and the $\mathrm{MgO}$ nanoparticles was prepared by cold pressing and by microwave sintering. The influence of $\mathrm{MgO}$ content ratio on properties was different in the case of as pressed green samples in comparison to sintered bodies.

Magnetic and mechanical properties of the sintered composite are related to formation of magnesium ferrite as well as volume distribution of residual $\mathrm{MgO}$ in dependence on initial $\mathrm{MgO}$ ratio.

\section{Acknowledgments}

This work was supported by the Scientific Grant Agency of the Ministry of Education, Science, Research and Sport of the Slovak Republic and the Slovak Academy of Sciences, project No. VEGA 2/0185/15 and the Slovak Research and Development Agency, project No. APVV-15-0115. This work was realized within the frame of the project "Advanced technology of preparing of micro-composite materials for electrotechnics", which is supported by the Operational Program "Research and Development" financed through European Regional Development Fund ITMS:26220220105.

\section{References}

[1] A.H. Taghvaei, A. Eabrahimi, K. Gheisari, K. Janghorban, J. Magn. Magn. Mater. 322, 3748 (2010).

[2] Y. Peng, J.W. Nie, W.J. Zhang, J. Ma, C.X. Bao, Y. Cao, J. Magn. Magn. Mater. 399, 88 (2016).

[3] S. Wu, A.Z. Sun, F.Q. Zhai, J. Wang, Q. Zhang, W.H. Xu, P. Logan, A.A. Volinsky, J. Magn. Magn. Mater. 324, 818 (2012).

[4] G. Delaizir, G. Bernard-Granger, J. Monnier, R. Grodzki, O. Kim-Hak, P.-D. Szkutnik, M. Soulier, S. Saunier, D. Goeuriot, O. Rouleau, J. Simon, C. Godart, C. Navone, Mater. Res. Bull. 47, 1954 (2012).

[5] PC. Angelo, J. Powder Metall. Min. 4, 1000129 (2015).

[6] W.L.E. Wong, M. Gupta, Technologies 3, 1 (2015).

[7] R. Bures, M. Fáberová, P. Kurek, M. Strečková, S. Dobák, F. Onderko, in: EURO PM 2015 - Sintering, Reims (France), EPMA, 2015.

[8] S.R. Spurgeon, J.D. Sloppy, Run-zhe Tao, R.F. Klie, S.E. Lofland, J.K. Baldwin, A. Misra4, M.L. Taheri, J. Appl. Phys. 112, 013905 (2012). 